\title{
Investigación, escritura y formación inicial del profesor ${ }^{1}$
}

\author{
Marinalva Vieira Barbosa (UFTM/CNPq) ${ }^{2}$ \\ Enoc Jesse Castro García -Traductor *
}

\section{Introducción}

En las universidades brasileñas es común que el alumno cuando llega a un curso de licenciaturas, frecuente una serie de disciplinas introductorias, entre ellas "Introducción a la Metodología Científica" - que tiene como fin durante un semestre, la exposición de reglas, métodos y sugerencias acerca de cómo escribir un proyecto, un resumen y un artículo - y "Lectura y Producción de Textos" - que tiene como fin, también durante un semestre, llevar al alumno a conocer las reglas de la escritura, los principales géneros académicos, los cuidados con la lengua modelo, etc.

Esas dos disciplinas, con algunas variaciones en los nombres y en los contenidos, generalmente despiertan en alumnos y profesores las mismas expectativas: tener una noción consistente de saber producir un texto y, principalmente, saber elaborar y desarrollar un proyecto de investigación.

Relacionado a la realización de esa metodología de enseñanza, el alumno también es introducido en un sistema de investigación en que, generalmente, se espera de él el contrato en un proyecto coordinado por un profesor. O sea, desde muy temprano es incentivado a hacer parte de grupos de investigación y a tomar como

\footnotetext{
${ }^{1}$ Este artículo presenta resultados de las primeras reflexiones desarrolladas en el proyecto de investigación, en progreso, titulado Entre el plagio y la autoría: ¿cuál es el papel de la universidad en la enseñanza de la escritura, investigación y formación de profesores? Este cuenta con el apoyo del CNPq - Proceso 401440/2011-7.

${ }^{2}$ Doctora en Lingüística por la Unicamp y Profesor Adjunto II de la Universidad Federal del Triángulo Minero. marinalvav@gmail.com

*Profesor de Matemáticas con Orientación en Física en el Grado de Licenciatura. Honduras, C.A.belza34@ hotmail.com
} 
suyo un caso, junto con la teoría, que un profesor ya venga desarrollando.

En ese escenario en que prevalecen concepciones de producción de conocimiento casi en serie, es común oír de los profesores universitarios de que el alumno no escribe, no tiene autonomía para pensar por cuenta propia y, sobretodo, tiene poca estima a lo que hace en la universidad. Cuando se trata de aquellos que irán a ejercer la docencia, la queja es mayor porque leen y escriben de modo frágil, o que consiste en una gran deficiencia en términos de comprensión de las teorías y la movilización de estas en la construcción de prácticas de enseñanza.

La lectura y la interpretación de las teorías con vista a la producción de un texto coherente y que contenga marcas de autoría, ha sido especie de punto inasequible a lo largo de los cursos de licenciaturas. Dicho de otro modo, los textos producidos, son en gran parte, muy semejantes porque resultan de un trabajo poco o casi nada creativo con el lenguaje, debido a las enunciaciones mal articuladas de otros textos.

Son producciones que, además de los problemas estructurales generados por las dificultades de dominio de la variedad modelo, no dejan entrever lo que su productor hizo, en términos de comprensión, con todo aquello que le es dado a leer a lo largo de un curso. Mediante tales dificultades, existen corrientes que defienden que las disciplinas introductorias, sobre todo las dos mencionadas al inicio de este tópico, deben funcionar como una especie de repositorio y retomar los contenidos que, a lo largo de los 11 años de escolarización, el alumno debería de haber aprendido sobre lo que es la lectura y la escritura. Por esa perspectiva, prevalece la concepción de que esas dos actividades pueden ser aprendidas por medio de una enseñanza instrumental.

Sin embargo, lo aprendido de la lectura, de la escritura y de la investigación está entrelazado y no es de orden de la instrumentalización o del aprendizaje por medio de repetición y/o alienación a una teoría o caso puesto por un profesor más experimentado. Lo aprendido de la escritura en la universidad no resulta solamente del dominio de reglas lingüísticas, así como el hacer 
de la investigación no ocurre del conocimiento de las metodologías acerca de cómo hacer un proyecto, etc.

Lo aprendido de la escritura admite que el alumno construya su propio medio para que, tomando el lenguaje y el conocimiento ofrecido a lo largo de cada disciplina, haga cálculos de posibilidades y dialogue con otros; dialogando, construya una lectura propia de aquello que lee y, consecuentemente, haga de ese tipo de interpretación la base principal de su producción escrita, lo que implica el rechazo de ser foyer de otros autores, y sobre todo, que logre asumir la posición de sujeto enunciador, no sólo en los espacios académicos, sino en los espacios sociales más amplios.

Investigar es moverse en el lenguaje y con el lenguaje para construir respuestas. De acuerdo con Larrosa (2004), cuando construimos respuestas e interpretaciones con las palabras, no estamos solamente nombrando las cosas, sino también dando sentido a aquello que somos, sentimos y vemos en relación con nuestro entorno. Ese proceso ocurre de la experiencia y genera experiencia.

Ante eso, en este artículo, analizaremos producciones escritas de alumnos de cursos de licenciaturas para demostrar como la ausencia de esa experiencia lleva la producción que Winnicott (1987) llamó de "lenguaje muerto", una vez que las producciones ahora son rellenadas solamente con impresiones personales y relatos resultantes de información acumulada, lo que producen redacciones genéricas, que no presentan punto de sustento - o punto de partida o de llegada.

Tales textos confunden al lector que busca reconocer, por ejemplo, en esos productores, un sujeto capaz de explicitar las marcas de su pensamiento sobre la experiencia vivida a través de la trayectoria de la escritura. Como conclusión, buscaremos delinear cómo la investigación genera un tipo de intimidad con la escritura. La intimidad es lo que lleva al sujeto a producir textos con una postura propia, capaz de revelar aspectos de sí mismo como sujeto intérprete y productor de un texto (MAIA In: PERROTTA 2004, p.10).

\section{1) Sean creativos, escriban textos con sus propias palabras}

Mediante la dificultad que el alumno presenta para producir un texto 
de acuerdo con el que es esperado, incluso en la universidad, es común que el profesor diga que deben ser creativos, además producir textos propios, y no solamente parafraseo de otros textos. Detrás de ese imperativo está la creencia de que ser creativo es escribir algo que vaya más allá de la repetición de las ideas teóricas comunes y que diga algo que aun no fue dicho en torno a un determinado tema.

Sin embargo, es poco claro, inclusive para los propios profesores, ese deseo de que el alumno sea creativo y use sus propias palabras para construir sus producciones. Son innumerables las teorías que demuestran que no hay nada que no sea producto de una construcción formada a partir del diálogo con algo que ya existe. Las palabras propias son, conforme Bakhtin (1929), palabras ajenas que, trabajadas e interpretadas, se transforman en palabras propias.

Además de ese deseo de que el alumno, durante un curso de licenciatura, asuma la condición de creador de algo nuevo, es necesario comprender que las producciones académicas han demostrado altamente una especie de privación en el trabajo de transformación preconizado por Bakhtin. El hecho de interpretar y de transformar la palabra ajena en algo propio, que no sea repetición, está en decadencia.

El sujeto contemporáneo que aparece en los textos académicos parece ser el resultado sobrepuesto de varios otros dichos. Muchas veces, en las producciones escritas aparecen enunciados críticos de los propios textos teóricos presentados por los medios de comunicación, sin embargo, aparece muy poco acerca de lo que el alumno hace con todo lo que le es dado.

Ante eso, en la universidad tenemos una generación de principiantes que no logran:

[...] elaborar sus proyectos de investigación por falta de intimidad con la escritura. En general, consideran el escribir, apenas como un medio para comunicar sus ideas, estas sin importancia y que merecen estudio y dedicación. Cuando encuentran una manera invariable de escribir, muchas veces entendida como lenguaje científico, construyen un texto en que la disociación entre el autor y su producción es evidente, creyendo haber encontrado un lenguaje común con sus semejantes. Son textos poco concluyentes, cansan al lector, el 
Investigación, escritura y formación inicial del profesor

cual desea conocer acerca del autor, así como identificar su estilo y sus marcas personales en el texto (MAIA, IN: PERRTTA 2004, p. IX).

Por las cosas señaladas por la autora, es posible afirmar que:

a) En las producciones académicas se hace presente un sujeto individualista, que se coloca como centro de las producciones $\mathrm{y}$, consecuentemente, cree que sus ideas son las que deben de valer;

b) El lenguaje científico/académico, al trabajar con la exigencia de la impersonalidad sin posibilitar que el alumno comprenda las bases de sustentación de esa concepción, colabora para la construcción de un texto genérico y sin marcas de singularidad; dicho de otro modo, el postulado de la muerte del autor que fundamenta la escritura académica, porque está mal explicado/ entendido por los alumnos principiantes, y han colaborado para la construcción de textos muertos;

c) La escritura es más vista como un medio de comunicación de ideas inclusive entre los profesores de las áreas humanas.

En ese contexto, se torna más difícil construir la comprensión de que, por medio de la producción de un texto, los sujetos dejan entrever más que el mismo acto de comunicar ideas; aun estamos lejos de construir una comprensión amplia que la del lenguaje, específicamente el lenguaje escrito, no es solamente medio de comunicación, es también medio de constitución del alumno como sujeto enunciador.

Escribir es lo mismo que inscribirse en el texto. Esa inscripción ocurre si hubiese un trabajo con un lenguaje que lleve a la producción de singularidad, ésta sólo es posible si el sujeto realiza gestos mínimos de interpretación de los dichos ajenos. Eso significa que escribir exige que el sujeto sepa entrar en el juego de lenguaje-cultura, "en las doctrinas de una formación discursiva", y desplazarse "con relación al sentido común, colocando algo propio en aquello que escribe". Lo aprendido en la escritura exige que el sujeto sepa "servirse del dicho de otros que constituyen su subjetividad sin que necesariamente se perciba, eso en fin, es desplazarse". (CORACINI, 2010, p. 36).

Ese es un aprendizaje primordial/necesario que se alcanza cuando se 
enseña a leer y escribir. Es también lo más difícil porque la sociedad contemporánea tiene como principal característica la individualización, la masificación del sujeto y de las informaciones. En ese contexto, el lenguaje tiende a ser visto no como lugar de inscripción del sujeto, sino como medio de registro y acumulación de información. La escritura que posibilita la inscripción del sujeto en sus propios dichos no puede ser obtenida/aprendida por medio de una enseñanza instrumentalizada o por la exposición de reglas acerca de cómo hacerla. Esa escritura carece de vivencia, de una experiencia de trabajo con el lenguaje para decir algo nuevo sobre un determinado tema.

\section{2) Breve comentario sobre lenguaje y constitución de sujetos}

La inscripción del sujeto en su propio texto, tal como apuntamos en el tópico anterior, resulta de la concepción de que el lenguaje es, al mismo tiempo, constituido y compuesto por los sujetos. El lenguaje, desde la perspectiva Bakhtiniana, es esencialmente dialógica. La escritura, por el trabajo y objetivos del sujeto, puede o no dejar percibir ese dialogismo que se hace presente por la materialización de uno o varios discursos en el texto. Este se torna, por lo tanto, en el resultado de estrategias lingüístico-discursivas unidas y que funcionan como un movimiento de filtraje en que el locutor busca restringir e impedir la proliferación de sentidos. Se trata de saber trabajar con y sobre un lenguaje para producirse una escritura propia, que no sea copia o parafraseo de textos ajenos.

Para Bakhtin (1979, p. 113), cualquiera que sea el enunciado, siempre estará limitado por las condiciones que lo sustentan. No existe una situación de lenguaje aislado de la "situación social más inmediata" que posibilite su surgimiento. En la situación inmediata, entran en acción imágenes y sentidos, construidos en la interrelación con el contexto mediato, asociados por el sujeto de la escritura a partir de la lectura que hace del lugar en que está establecido y de las razones por las cuales está enunciando.

Así, al analizarse un enunciado/texto, importa preguntar por aquello que él produce y por lo qué lo produce: la construcción de los sentidos, las entonaciones valorativas marcadas por una $u$ otra forma de decir, el tema que, para ser comprendido, exige que se vea para el texto, 
Investigación, escritura y formación inicial del profesor

para el enunciado, en toda su amplitud.

En síntesis, por ocupar lugares específicos, el sujeto no trabaja de forma indistinta con el lenguaje. Al contrario, textualiza el discurso anclado en diversos discursos y sujetos. Esa relación trae con la escritura, las marcas de su tiempo, de los procesos de constitución del sujeto que escribe, ya que el lenguaje, sea escrito o hablado, no se produce en el vacío, sino dentro de una situación histórica concreta. De ahí, la defensa hecha aquí de que, para comprender las producciones presentadas por los alumnos a lo largo de los cursos de graduación, es importante relacionarlas a la temporalidad de su producción.

\section{3) La pobreza de la experiencia como preocupación de la escritura académica}

La temporalidad de producción de la escritura se opone radicalmente al bordón capitalista de que "el tiempo es dinero" y que, por eso, cuanto menor fuera el tiempo que se dispensa para una actividad, más ganancia hay en producción. La escritura exige que el sujeto se instale en una posición de reflexión amplia. Cuanto más tiempo el sujeto se está dando vuelta en una lectura, cuanto más escribe y reescribe un texto, mayores son las oportunidades de que el producto de ese trabajo sea también constitutivo del sujeto y del lenguaje.

El resultado de lo aprendido de la escritura puede ser nombrado, de acuerdo con Larrosa (2004), como "saber de la experiencia". Con las palabras del autor:

[...] Podríamos decir de inicio que la experiencia es en español ‘o que nos pasa'. En portugués se diría que la experiencia es 'lo que nos acontece'; en francés la experiencia sería 'ce que nous arrive'; en italiano 'quello che nos succede' o 'quello Che nos accade'; en inglés 'that what is happening to us'; en alemán 'was mir passiert'. La experiencia es lo que nos pasa, o lo que acontece o nos toca. Cada día pasan muchas cosas, sin embargo, al mismo tiempo, casi nada nos pasa. Se diría que todo lo que pasa está organizado para que nada nos pase. Walter Benjamín, en un texto célebre, ya certificaba la pobreza de experiencias que caracteriza nuestro mundo. Nunca se pasarán tantas cosas, pero la experiencia es cada vez más rara (LARROSA, 2004, p. 154). 
La experiencia es aquello que toca, hace que el sujeto sienta en el cuerpo las implicaciones de su involucramiento con su propia producción. La escritura que posibilita la constitución de esa experiencia trae el germen de las palabras de los demás.

Sin embargo, por la perspectiva puesta por Larrosa, la experiencia, en los días actuales, está en decadencia debido a la acumulación de información. Cotidianamente, existe el imperativo para que seamos consumidores ágiles de las muchas informaciones que nos rodean. Prevalece la concepción de que el caso es posible para aquel que, no sólo consume con agilidad las informaciones, sino que produce con dichas informaciones una especie de reservatorio para ser consultado siempre que sea necesario. He allí que surgen, el valor y el caso de los sitios web que acumulan millones de datos informativos.

Ocurre que la información, o su acumulación, no generan experiencia, al contrario, no deja lugar para aquella. El sujeto informado sabe muchas cosas - tanto que no es difícil percibir en las aulas de clases alumnos informados, que tienen una opinión crítica sobre varios asuntos -, pero no se siente implicado con ese saber que acumula.

En ese sentido, la dificultad de escritura, que pude ser localizada en la universidad y en las etapas de la escuela básica, no ocurre de una incapacidad de aprender, sino de la falta de experiencia para producir una escritura propia. Esa dificultad ocurre exactamente porque, en la contemporaneidad, los espacios de constitución del sujeto y del lenguaje se fragmentaron, individualizaron; o sea, las utopías políticas comenzaron a carecer de importancia.

Consecuentemente, en el trabajo con el lenguaje, el sujeto de la información queda cautivo al plano repetitivo de la frase o de la oración como célula de la lengua, perdiendo con eso la sensibilidad para percibir que el lenguaje comprende también otro plano: la no repetitividad de la enunciación, que hace a la palabra ser siempre diferente en cada texto. En una lectura de ese contexto para comprender cómo se da la constitución de la experiencia, Larrosa afirma:

Una vez vencido y abandonado el saber de la experiencia y el conocimiento de la existencia humana, tenemos una situación 
Investigación, escritura y formación inicial del profesor

paradoxal. Una enorme inflación de conocimientos objetivos, una enorme abundancia de artefactos técnicos y una enorme pobreza de esas formas de conocimiento que actuaban en la vida humana, en ella introduciéndose y transformándola. La vida humana se hizo pobre y necesitada, y el conocimiento moderno ya no es el saber activo que alimentaba, iluminaba y guiaba la existencia de los hombres, sino algo que flota en el aire, estéril y desligado de esa vida en que ya no puede encarnarse (2004, p. 131).

Como consecuencia, tenemos un sujeto contemporáneo que:

[...] además de ser un sujeto informado que opina, además de estar permanentemente agitado y en movimiento, es un ser que trabaja, quiere decir, que pretende conformar el mundo, tanto el mundo "natural" como el mundo "social", tanto la "naturaleza externa" como la "naturaleza interna", según su saber, su poder y su voluntad. [...] El sujeto moderno se relaciona con el acontecimiento del punto de vista de la acción. Todo es pretexto para la actividad (2004, p. 121-123).

Ese sujeto elogiado por Larrosa trae consigo una historia de constitución que resulta de esa fractura fundamental y, por eso, evidencia, al mismo tiempo, el desgaste que impregna y constituye el espacio social en la contemporaneidad. Así, cuando se admite/asume que un sujeto se constituye por medio de, y en el lenguaje, entendiendo el propio lenguaje ya como una actividad constitutiva, se admite también que el sujeto contemporáneo es constituido por medio de relaciones cuyos "acontecimientos son dados en forma de ofensa, de estímulo, de sensación pura, de vivencias instantáneas puntuales y desconectadas" (IDEM).

La velocidad con que nos son dados los acontecimientos y la obsesión por la novedad que caracteriza el mundo contemporáneo impide, muchas veces, el establecimiento de interpretaciones significativas. Eso también dificulta el trabajo con la memoria discursiva ya que cada acontecimiento es inmediatamente sustituido por otro igualmente apasionante e importante, pero que no deja marcas pasibles para ser transformadas en experiencias de nuevas vivencias. Tanto que, para Ponzio (2010), en los espacios de enseñanza y aprendizaje: 
La lógica de la pregunta y de la respuesta es dominante hoy en día, o sea, la lógica de querer decir y querer oír; ya lo podemos ver en los lugares de aprendizaje y de formación, en la escuela, en la universidad. Comienzo los cursos y, en el primer día, un estudiante que se presenta al final de la clase, me pregunta: "profesor, ¿cuándo piensa que será la prueba?". El objetivo de ese estudiante es aquel de ser interrogado. Hoy, la propaganda más eficaz para una universidad es el slogan: “ $¡$ Veinte pruebas en cuatro meses!" sin embargo, ¿dónde está la calidad?, ¿dónde está la palabra?, ¿dónde está el magisterio?, ¿dónde está la enseñanza? (PONZIO, 2010, p. 25).

O sea, que debido a que el universo de la información es demasiado encerrado, el lenguaje que aparece en las producciones académicas perdió su carácter de desafío, de provocación, en relación a las identidades totalitarias y cerradas. Se suma a eso el hecho de que, en la mayoría de las veces, la propia universidad presenta su propio texto teórico al alumno como verdades incuestionables. Así, porque es un sujeto constituido por medio de ese lenguaje predominantemente informativo, el alumno tiene dificultades para preguntar todo lo que parece sólido y definitivo en términos de conocimiento. En la producción de textos, casi siempre introduce lo que está en la superficie de la lengua y reproduce la palabra ajena como pequeños monumentos teóricos o informativos que no merecen ser escuchados muy profundamente, porque ya están explicados, interpretados por este o aquel teórico/profesor, por este o aquel medio de comunicación.

\section{4) El difícil arte de dialogar con el otro para producir una palabra propia}

\subsection{Interpretar como un acto de consumo}

Para continuar, serán analizadas algunas producciones de ese sujeto contemporáneo señalado en tópico anterior. Las producciones resultaron de actividades de escritura desarrollada con cuatro grupos de alumnos de los cursos de licenciaturas de una universidad de la Región Sudeste de Brasil. En la actividad, fue solicitado que escribiesen una carta argumentativa que concordara o discordara con la crónica transcrita a continuación.

El pedido era el siguiente: a) Si usted no concuerda con el autor, 
escriba una carta discordando de su opinión con relación a la situación de los "sin tierra"; b) Si usted está de acuerdo, escriba una carta para el diputado, autor de la afirmación de que "Brasil termina con los 'sin tierra' o los 'sin tierra' terminan con Brasil" (PERROTTA 2004). Veamos el texto de base y en seguida algunas producciones de los alumnos.

Los "sin tierra" insisten en existir, lo que se está volviendo una provocación intolerable. No hay empleo para ellos en las ciudades, no hay tierra para ellos en el campo, y aun así, ellos insisten en no tomar la única medida que ni siquiera apenas resolvería su problema ni asegurar la paz social, tampoco devolvería la tranquilidad a la comunidad y a las clases productoras, el suicidio colectivo. No pueden decir que no son responsables por la situación a que llegaron. Con un mínimo de previdencia habrían nacido en Canadá, evitando así, el actual clima de confrontación. Negandose a desaparecer voluntariamente, los "sin tierra" dan una lamentable prueba de intransigencia y no pueden quejarse de la radicalización del otro lado (Veríssimo, "Provocación" El Estado de São Paulo, 24/04/ 1998, Cuaderno 2, p.2).

Es importante resaltar que uno de los rasgos característicos de la obra de Luis Fernando Veríssimo, periodista y escritor, es el humor que se presenta en las más variadas formas. Utilizando un lenguaje sencillo y bien elaborado, el autor trata de asuntos cotidianos, que comúnmente pasan desapercibidos a los ojos más desatentos. Al mismo tiempo, exterioriza conflictos políticos, culturales e ideológicos de la sociedad brasileña por medio de un lenguaje extremamente crítico. $\mathrm{O}$ sea, a través de la astucia, del buen humor, de la ironía, del libertinaje, de la incredulidad, de la exageración y de lo absurdo, Veríssimo no sólo juega con las palabras, con los sentidos y con las significaciones, sino que critica las creencias del lector, despertando en él emociones, intenciones y seducciones.

De acuerdo con PERROTTA (2004, p.39), en el texto de arriba, Veríssimo, usando la ironía para denunciar un grave problema social de Brasil - la distribución de tierras -, incorpora la voz de un personaje nazista $\mathrm{y}$, a partir de eso, critica la manera de pensar de los grandes terratenientes. Por medio de esa estrategia, coloca 
para el lector, de forma polémica, la gravedad de la situación de las clases sociales menos favorecidas $y$, al mismo tiempo, "descalifica aquellos que perpetúan discursos de esa naturaleza, poniéndolos en ridículo".

De la lectura de la crónica de arriba, surgieron las siguientes producciones, que son representativas de cerca de $90 \%$ de las interpretaciones realizadas por los alumnos.

\section{Texto 1}

Estimado Veríssimo, no concuerdó con su opinión, de terminar con que los "sin tierras" representan un grupo de personas que luchan por igualdad de división de tierras. Los "sin tierra" a veces traspasan los límites, con invasión de propiedades privadas de personas que compraron con sus propios esfuerzos, y llegan a ser hasta agresivos con los propietarios de las propiedades.

\section{Texto 2}

Señor Veríssimo, me permito decir la gran decepción que me invadió al leer su artículo, con todo respeto, usted fue muy infeliz escribiendo tan grande crueldad. Suerte la suya que no nació en una familia de "sin tierra". Quiero recordarle que nadie escoge nacer rico o pobre, o incluso "sin tierra", por eso no es el "suicidio colectivo" que va entre las diferencias de clases. Seamos racionales, ¿imagínese si esta fuera la única medida para la solución de estos asuntos sociales? Ciertamente no tendríamos problemas con la superpoblación. Es muy fácil escribir artículos que, de forma indirecta, no dejan de incentivar la intolerancia y la violencia. Espero que usted piense bien en lo que escribió, y en lugar de escribir inutilidades, piense en cómo podríamos ayudar a mejorar la situación de las clases menos favorecidas.

\section{Texto 3}

Estimado Veríssimo, no pude dejar de preguntar sobre su opinión al respecto de la situación de los "sin tierra" en Brasil, me sorprendo bastante con su intolerancia y arrogancia sobre el asunto. Para hacer una política terrateniente en Brasil es necesario la organización de masas sociales para imponer políticas democráticas de compartimiento de tierras. Sin esas masas sociales, mujeres negras, protestantes y muchos más no tendrían 
sus derechos garantizados por ley, estos fueron discriminados y hoy son reverenciados por sus luchas. Por lo tanto, estimado Veríssimo, no se preocupe, el periódico no publicará titulares sobre suicidios colectivos de "sin tierras", eso lo garantizo al menos mientras la sociedad esté sana y, es suficiente leer documentos de Freud para entender mi razonamiento.

Esas producciones ofrecen muchas posibilidades de análisis (y para escandalizarnos también). No es difícil percibir que les falta una serie de operaciones textuales y discursivas necesarias para la construcción de un texto cohesivo y coherente, tales como: puntuación, conectores, organización temática local y global, y modalización; de lo contrario presentan problemas en la elaboración de argumentos contradictorios, en las inferencias y presuposición, que únicamente sirven para citar los más evidentes.

Sin embargo, lo que más despierta atención inmediata es la lectura literal hecha de la crónica a pesar de los indicios que prohíben ese tipo de lectura literal, de acuerdo con Marchuschi (2008), es "un sentido básico que entendemos cuando usamos el lenguaje en situaciones naturales. No se trata del sentido que da el diccionario ni de una oposición al sentido figurado, sino de aquel sentido que es construido como preferencial" (p. 235). Por esa perspectiva, la lectura literal exige un contexto como base para su realización.

De los 110 alumnos que hicieron la actividad escrita, conforme lo dicho hasta ahora, $90 \%$ criticó al autor de la crónica por defender el suicidio colectivo de los "sin tierra". O sea, el 90\% leyeron que el autor estaba de hecho defendiendo la muerte de los "sin tierra". Ante lo pedido, para que señalasen los elementos textuales y discursivos que fundamentaron esa interpretación, varios alumnos afirmaron que, al ver el término "suicidio colectivo" en texto cuyo tema era los "sin tierra", asumieron que era preciso criticar. Otro fue más largo en la explicación: “ese asunto (el de los 'sin tierra') aparece siempre ligado a algún tipo de crítica, por eso hallé importante criticar al autor".

La crónica leída, además de haber sido escrita por un autor conocido, fue publicada en un diario de gran circulación, y de renombre en la política de derecha. En Brasil, los medios de 
comunicación en general presentan materias acerca de las acciones del movimiento de los "sin tierra", y, principalmente, de las confrontaciones que tales acciones generan con los terratenientes. Es común también que segmentos de la prensa asuman posiciones críticas con relación al movimiento. Ante eso, los alumnos de forma general, al leer el texto, se fijaron mucho más en la reserva de informaciones que ya poseían; y el trabajo con los recursos lingüísticos, la ironía dibujada en la crónica no funcionó como elemento de prohibición de esa interpretación literal - la de que el autor estaba en contra de los sin tierra".

En las explicaciones ofrecidas por los propios alumnos para esa interpretación literal, aparece un sujeto que tiene información acerca del tratamiento dado al tema del texto, pero no sobre el tema del texto. Se trata de un sujeto que, al identificar en el texto un término lingüístico ("suicidio colectivo") y un tema aparentemente conocido (sin tierra), hace una interpretación anclada a una especie de reserva general de información. El texto, lo lingüístico, como espacio no tan libre de interpretación, es poco considerado. Dicho de otro modo, texto y autor no representan el obstáculo necesario que impide la transformación de la lectura en una especie de "vale todo".

Al mismo tiempo en que el texto del otro se configura como un cuerpo que no ofrece resistencias, el texto producido por el alumno asume la condición de monstruo Frankenstein. De tal modo que en el final de la tercera producción transcrita arriba, aparece el siguiente enunciado: "Por lo tanto, estimado Veríssimo, no se preocupe, el periódico no publicará titulares sobre suicidios colectivos de "sin tierras", eso lo garantizo al menos mientras la sociedad esté sana y, es suficiente leer documentos de Freud para entender mi razonamiento." Una vez que no hay una secuencia lógica de argumentos, la referencia a Freud aparece como una especie de remiendo utilizado para concluir.

Para ocupar la posición de un sujeto informado, ese alumno posiblemente ya haya leído algún texto que haga referencia a Freud; o incluso haber leído resúmenes introductorios de la obra de ese autor. Sin embargo, así como no van más allá del primer sentido del término "suicidio colectivo", también no van más allá 
Investigación, escritura y formación inicial del profesor

de saber de la existencia de Freud y, principalmente, de saber que es importante tal referencia en el mundo académico.

En ese trabajo de lectura y escritura, el alumno toma la palabra como algo posible de identidad, universalización y pertenencia a la única especie de género; pero no sólo la palabra pasa a ser algo que puede ser reducido a lo idéntico, a una imagen fija y total.

Es muy común que ese mismo alumno, siempre que lee un texto que presenta términos como sociedad, gobiernos, etc. o critica un caso social específico, trae esos temas para el contexto presente y comienza a hablar "críticamente" de los dilemas políticos sociales de la sociedad actual. El gesto de leer es siempre, y mayoritariamente a partir de las informaciones más amplias que acumuló, y nunca de la relación entre informaciones mucho más amplias y, sentidos e informaciones contenidas en el texto. En la tríada autor-lector-texto, lee considerando solamente a sí mismo como lector que acumuló un equipaje de informaciones escuchadas o que le son dadas como interpretaciones siempre únicas y verdaderas del mundo.

De allí, la información “ese asunto (el de los 'sin tierra') aparece siempre ligado a algún tipo de crítica, por eso hallé importante criticar al autor". Ese discurso lo coloca en la posición de un sujeto ultra-informado, sobreabundante de opiniones, siempre listo a criticar/opinar y, al mismo tiempo, con poca experiencia en el trabajo con el lenguaje. De ese lugar, interpreta a partir de la acumulación de informaciones dadas ya como supuestas interpretaciones del mudo.

Esa acumulación de informaciones/interpretaciones pasteurizadas, ya listas y servidas por medio de una especie de fest food (festival de comida), cuando es sumado al pequeño equipaje de saberes que ese alumno construye en la escuela sobre el funcionamiento del lenguaje, resulta en una lectura equivocada de otros textos. En lo que respecta a la escritura, si consideramos las exigencias que definen cómo debe ser el lenguaje académico, tenemos algo que casi no es texto; o en otras situaciones, tenemos textos que son meras reproducciones. 


\subsection{La escritura como reproducción}

Nuestra habla, es decir, nuestros enunciados (que incluyen las obras literarias), están repletos de palabras de otros, caracterizadas, en grados variables, por la alteridad o por la asimilación, caracterizadas, también en grados variables, por un empleo bien ejecutado y modelado. Las palabras de los demás introducen su propia expresividad, su tono valorativo, que asimilamos, reestructuramos, modificamos (BAKHTIN 1979, p. 314).

El sujeto se incorpora como tal en el diálogo, en la interacción con el otro. Las palabras son siempre del otro y propias. No existe la posibilidad de un texto que sea producido con palabras nunca antes dichas. Sin embargo, de acuerdo con Scheneider (1990, p. 61), existe una gran "degradación con respecto a los procesos y procedimientos" de reproducción en la contemporaneidad de la voz y de la palabra del otro, "notablemente en los trabajos universitarios. La modestia de los grandes letrados de ayer contrasta con el amoralismo que actualmente caracteriza el uso de las citaciones o de las referencias en las ciencias humanas" (IDEM).

De acuerdo con ese autor, las reproducciones en los siglos XIX y $\mathrm{XX}$, principalmente, ocurrían no por la ausencia de lectura y de saber, sino porque era inevitable la transformación y nueva creación tras el almacenamiento que la lectura producía. Esa nueva creación parece ser el punto que se perdió en la universidad contemporánea, una vez que, por caminos diferentes, prevalece la misma lógica de la lectura como medio de acumulación de información y no como recurso para la construcción de un saber propio.

[...] en los moldes como la formación viene conducida, así como la orientación para la escritura de textos en la universidad, poco se exige de lectura en profundidad, de manera que es común que los textos citados en la universidad no hayan sido comprendidos, ni siquiera al ser leídos. Por ejemplo, la secuencia de apellidos y fechas enlistadas sobre un asunto para atender a las exigencias formales de presentación del esqueleto teórico del trabajo, puede haber sido recortada de algún lugar, a veces de un archivo del 
Investigación, escritura y formación inicial del profesor

propio orientador, y pegada, o haber sido leída rápidamente para reconocer los términos claves, pero sin la debida comprensión (BARZOTTO, 2012, prelo).

La lógica de la producción como medida para definir derecho a financiamiento, a la autoridad para hablar sobre un determinado tema, está volviendo la escritura un acto similar a la elaboración de un edredón de retazos. Además de eso, la reproducción acrítica de la palabra de los demás se está volviendo un problema porque las informaciones, los textos, las obras teóricas se quedaron voluminosas, accesibles y frágiles en términos de protección cuando se piensa en el movimiento "recorta y pega".

Ese fácil acceso funciona como una invitación para el sujeto, apretado por el peso de la página en blanco y mediante la necesidad de escribir, sumergirse en los laberintos textuales para forjar como su único extracto, un párrafo o incluso todo un texto. Parafraseados (o incluso copiados) de forma poco cuidadosa - ya que el párrafo es autorizado por la propia universidad - esos textos pasan a ser exhibidos como producciones acéfalas de un trabajo de creación y/o nueva creación que lleve la emergencia nuevamente.

Lo aprendido del párrafo mal reproducido es adquirido por el alumno de graduación muy temprano y ya en las producciones que presenta para conclusión de disciplina, o en la escritura de textos y proyectos de iniciación científica, demuestra la creencia de que reproducir la voz de un autor conocido es un modo de probar que aprendió a manejar el discurso académico. Tanto que, en uno de los textos analizados en el tópico anterior, el alumno menciona a Freud, sin establecer cualquier relación entre el decir de ese autor y el asunto discutido. Esa referencia, aunque equivocada, no es ingenua. Ella revela indicios de una percepción acerca del funcionamiento discursivo de las producciones universitarias.

En la universidad contemporánea, las reproducciones de contenido, de teorías y de ideas han asumidos contornos preocupantes cuando se considera que la escritura no es únicamente el gesto de poner palabras en el papel, pero también se constituye y es constitutiva de la manera cómo el sujeto percibe, 
analiza, critica y se posiciona sobre preguntas y temas que hacen parte del contexto en que está insertado. La escritura es un medio de ofrecer respuestas propias sobre temas investigados, lecturas hechas, etc. En su defecto, la universidad pierde su sentido fundamental - o de producir conocimiento.

Considerando los fragmentos a seguir, es posible concluir que la escritura académica, en buena parte, en la graduación y en la posgraduación, sintetiza lo que Maia (2004) definió como textos que no posibilitan al lector: a) comprender las maneras de cómo el sujeto pensó aquello que escribió; b) conocer las afiliaciones teóricas de quien escribió; c) identificar un estilo y las marcas personales que funcionan como indicios de autoría.

A continuación se presentan algunos ejemplos de cómo esa producción gana materialidad a lo largo de la vida académica.

1) Fragmentos de textos de ensayo de alumnos de graduación

\section{Alumno: 01}

"Decir que la razón caracteriza al humano, es una visera, porque nos deja ciegos frente a la emoción, que queda desvalorizada como algo que niega lo racional."

Texto de Maturana que el alumno 01 reprodujo:

"Decir que la razón caracteriza al humano, es una visera, porque nos deja ciegos frente a la emoción, que queda desvalorizada como algo animal o como algo que niega lo racional." (MATURANA; 2002, p. 15).

\section{Alumno: 02}

"La educación es un proceso continuo que dura toda la vida, y que hace de la comunidad donde vivimos un mundo espontáneamente conservador, al cual el educar se refiere. Eso no significa, que el mundo del educar no cambie, pero sí que la educación, como sistema de formación del niño y del adulto, tiene efectos de larga duración que no cambian fácilmente. "

Texto de Maturana que el alumno 02 reprodujo:

"La educación es un proceso continuo que dura toda la vida, y que hace de la comunidad donde vivimos un mundo espontáneamente conservador, al cual el educar se refiere. Eso no significa, que el mundo del educar no cambie, pero sí que la educación, como sistema de formación del niño y del adulto, tiene efectos de larga duración que no 
Investigación, escritura y formación inicial del profesor

cambian fácilmente." (MATURANA; 2002, p. 29).

2) Fragmentos de ensayo de un máster

[...] Para Saussure (2008), la lengua es un sistema de signos los cuales se diferencian de acuerdo con su relación con otros signos. La lengua es un fenómeno social debido al hecho de ser el producto de un acuerdo establecido. [...] Chomsky (2005), el fundador de la gramática generativa y de la revolución cognitiva, concibe la lengua como un objeto puramente mental del ser humano. [...] En sus estudios, Vygotsky (1998) resalta que el lenguaje es el instrumento por excelencia que nos hace actuar, pensar y modificar nuestras relaciones sociales. [...] Según Piaget (1986) el lenguaje es un sistema el cual representa la realidad y hace posible la comunicación, la transmisión de información y el intercambio de experiencias entre individuos.

\section{3) Fragmento de texto de un doctor}

[...] Charaudeau (2004) recuerda que, en los campos de Análisis del Discurso, de la semiótica y del Análisis Textual, hay por lo menos cuatro puntos de vista de donde se pueden comprender los géneros: funcional, enunciativo, textual y comunicacional. El punto de vista funcional trae, entre otras, las clasificaciones de Jakobson (1975), aun hoy muy utilizadas en la comunicación, y Halliday (1978). [...]. El punto de vista enunciativo parte de la oposición que Benveniste (1995) propuso entre discurso e historia, una oposición que, como recuerda Charaudeau (2004, p. 250, cursivas del autor), es "frecuentemente reformulada en Discurso vs. Narrativa". Benveniste trata de las relaciones de tiempo y propone dos planos de enunciación, uno histórico y el otro discursivo. De forma resumida, dice que la enunciación histórica es reservada al lenguaje escrito y "caracteriza la narrativa de los acontecimientos pasados. [...] se trata de la presentación de los hechos acontecidos en un cierto momento de tiempo, sin ninguna intervención el locutor en la narrativa" (BENVENISTE, 1995, p. 262).

En un análisis de los tres fragmentos anteriores, no es difícil concluir que la reproducción funciona como una especie de motor de la escritura. El alumno de graduación copia el texto leído porque aun no adquirió en la universidad dominios de las estrategias de citar y/o parafrasear tal como vigente. Con el avance de los niveles académicos, la copia pierde la posición de moneda fuerte para el párrafo. Esta, aunque es autorizada y vista como un recurso legítimo de construcción de la escritura, es esparcida por todo el texto, no restringiéndose a 
una u otra citación directa o indirecta.

Es importante destacar que no se está discutiendo aquí la pregunta de la reproducción. Lo que se busca es demostrar que, en esas producciones, hay un exceso de anclaje en la voz del otro. Además de eso, hay una forma de leer la teoría que se repite, cual sea, la lectura destituida de crítica. Los autores teóricos son presentados, sus voces son modificadas unas en las otras, sin notarse las diferencias fundamentales de cada una de sus concepciones. En el segundo fragmento, por ejemplo, varios autores son puestos uno al lado del otro, pero prevalece la falta de comprensión, inclusive de los propios conceptos enlistados.

La inscripción del sujeto en el propio texto no aparece, una vez que el resultado de la escritura es una especie de descripción de las ideas de otros. La escritura como resultado de interpretación exige que quien escribe vea el propio texto y el de los teóricos leídos como una arena que materializa voces que están en conflictos y/o complementariedad. Dicho de otro modo, la articulación entre teóricos diferentes, por ejemplo, exige cuidados, una vez que tiene fundamentos diferentes, los cuales diferencian los análisis y resultados, incluso cuando los fenómenos abordados son los mismos en la práctica.

Saussure, Chomsky, Vygotsky y Piaget hablan de lenguaje, pero los fundamentos de sus concepciones acerca de ese objeto de estudio son diferentes, por lo tanto, un texto académico que los coloque juntos, carece en lo más mínimo, de presentar una lectura crítica de lo que cada uno de estos pensadores comprende por lenguaje.

En la universidad, la lógica de reproducción de la voz autorizada ha promovido una especie de ceguera y las producciones muestran a un sujeto con dificultades para percibir que las palabras tienen sus desafíos internos, y por eso, para apoderarse de ellas es necesario asumir la posición de quien se siente desafiado, atravesado por otros sentidos $y$, sobre todo, atravesado por el deseo de modificar y ser modificado por lo que leyó y escribió.

Ante eso, se vuelve necesario cuestionar los sentidos y los objetivos de enseñar a leer y escribir en disciplinas como las mencionadas en la introducción de este artículo o por medio de la práctica de la 
investigación. Crear espacio para la palabra del alumno y, al mismo tiempo, enseñarle a dialogar con la palabra de otro (texto, autor, etc.) es una exigencia de nuestro tiempo. Eso debido a que prácticas monológicas de escrituras vigentes en la universidad, cuando son añadidas al tagarelismo crítico vigente en nuestra sociedad, hacen surgir un sujeto informado, repleto de palabras ajenas, pero con poca experiencia para seleccionar, interpretar y construir sus propias palabras.

En ese sentido, la universidad no puede seguir reclamando de la escuela básica de que el alumno no aprendió a leer y escribir. Precisa también asumir que, en su interior, leer, escribir, preguntar e investigar son aprendizajes que necesitan ser, no sólo trabajados nuevamente, sino también revestidos de nuevas ideas. No se puede dejar al alumno que llega a los cursos de posgrado, creer que toda lectura es posible y aceptable, sobre todo en aquellos que forman futuros profesores.

El autor de la crónica citada en el tópico "La interpretación como consumo" no defendió el suicidio de los "sin tierra". Por las interpretaciones presentadas, vivimos un tiempo en que enseñar el lenguaje admite también ser intransigente en la enseñanza de que el texto, autor y el propio profesor, son el otro del alumno. Ese otro trae interpretación de palabras para la lectura y escritura, además los límites y resistencias en el trabajo que hace con y sobre el lenguaje.

En ese sentido, vale afirmar que, en la contemporaneidad, además de enseñar el lenguaje, el funcionamiento de los recursos lingüísticos, es importante que el profesor también sepa construir para que el alumno comprenda que, para producir efectos de sentidos, el lenguaje:

[..] requiere un gesto de interrupción" [...] requiere lo aprendido acerca de cómo "parar para pensar, para ver, parar para escuchar, pensar más lento; parar para sentir, sentir más lento, demorarse en los detalles, suspender la opinión, suspender el juicio, suspender la voluntad, suspender el automatismo de la acción, cultivar la atención y la delicadeza, abrir los ojos y los oídos, hablar sobre lo que nos pasa, aprender la lentitud, escuchar a los demás, cultivar el arte del encuentro, hacer silencio, tener paciencia y darse tiempo y espacio (LARROSA, 2004, p. 160).

Eso requiere un trabajo de enseñanza que lleve la construcción de 
saber y no únicamente almacenamiento de informaciones.

\section{5) La investigación como posibilidad de producción de una palabra propia ${ }^{3}$}

En la introducción de este artículo, fue hecha una breve exposición acerca de cómo la universidad trabaja la enseñanza de la lectura, de la escritura y de la investigación. Se trata de un modelo que, aunque reconozca la interdependencia de esas actividades, nos las coloca como elementos que necesitan caminar juntos en el proceso de constitución del aprendizaje y formación del futuro profesor. Generalmente, la escritura y la lectura son puestas como saberes amplios, necesarios para la producción de textos. La investigación es el lugar legítimo de la producción de conocimiento. Lo aprendido de la lectura y de la escritura por medio de la investigación es un aspecto poco explorado.

En la continuidad del texto, presentamos un cuadro analítico acerca de las prácticas de lectura y escrituras llevadas por el alumno para la universidad, y esas cuando son agregadas al modelo vigente de escritura académica, resultan en una especie de producciónreproducción. Tales prácticas, conforme a lo demostrado, son constituidas con base en las concepciones, valores e ideologías vigentes en la sociedad contemporánea. Ante eso, la metodología de la enseñanza de la lectura, de la escritura y de la investigación que, muchas veces, aun se sujeta a la enseñanza de los aspectos formales de la lengua, así como a la enseñanza de las reglas de cómo hacer investigación, no es suficiente para superar la producción de un texto

\footnotetext{
${ }^{3}$ En las últimas décadas, la discusión sobre la relevancia de la investigación en la formación inicial ganó distinción en el medio académico brasileño; también ganó mucha inversión de las agencias de promoción; hoy, en muchas universidades, existe un número alto de becas para que el alumno desarrolle proyectos de iniciación a la investigación bajo la orientación de un profesor. Sin embargo, el reconocimiento de la importancia en la investigación en la graduación y, también, la creciente inversión en esa práctica de formación no están siendo seguidos por un debate sobre la necesidad de volver a pensar en el modelo de formación por la investigación vigente en las universidades. De modo que, en la graduación, la forma de presentar al alumno principiante las reglas de investigación y escritura es por medio de la realización de las disciplinas de Metodología Científica y Lectura y Producción de Textos. Para la realización de éstas, aun tiende a prevalecer el modelo instrumentalizado, que tiene como objetivo proporcionar la formación/información acerca de cómo hacer, y las reglas que deben ser seguidas. En ese modelo vigente, el alumno luego de salir, toma el conocimiento de las reglas de cómo hacer un proyecto de investigación. Al final del semestre, cuando ya están unidas ambas disciplinas, presenta un proyecto de investigación, escrito muchas veces no para ser desarrollado, sino para ser una demostración de su comprensión y dominio de las reglas de funcionamiento de ese género académico. Generalmente, ese proyecto es guardado para ser desarrollado en otro momento o queda únicamente como cumplimiento de una ruta de aprendizaje. Es común, con la creciente inversión en becas de iniciación a la investigación, el alumno, ya en el segundo año del curso, ser llamado por un profesor para desarrollar proyectos de iniciación científica. Dentro de ese modelo de desarrollo de investigación, debe vincularse a un grupo de un profesor y, bajo orientación, pasar a desarrollar un proyecto de iniciación. El alumno entra en el proyecto como una especie de ayudante, como tal, pasa a ser responsable por la colección y transcripción de datos.
} 
improductivo, destituido de una lectura no socializada.

La investigación como posibilidad de constitución de una palabra propia $y$, sobre todo, como elemento que permite que el futuro profesor ocupe una posición singular frente al conocimiento, necesita desarrollarse sobre otros parámetros, una vez que el modelo vigente, de hecho, reafirma la práctica de lectura y escritura que se asemeja al acto de consumo. La investigación, si se concibe en bases diferentes, puede ser un medio por el cual es posible ofrecer pequeñas respuestas para ese estado de cosas. Por medio de ella es posible que el futuro profesor cambie su posición subjetiva, saliendo así de la posición de consumidor incompetente de los conocimientos producidos en la universidad.

La investigación, tal como es defendida aquí,

[...] se centra en la defensa de que la graduación es un momento en que el alumno tiene derecho a hacer investigación en cada disciplina que cursa. Para eso, cada disciplina sería conducida con la realización de una investigación a lo largo de su desarrollo. O sea, al presentar el programa de disciplina en el primer día, el profesor ya solicitaría a los alumnos que informasen por escrito lo que pretenden investigar durante el semestre o el año lectivo. La información no necesita ser en forma de proyecto, basta que quede clara la propuesta de investigación y la relación con la disciplina, siendo común que el alumno necesite orientación para ajustar su propuesta al foco de la disciplina. Sabemos que esta propuesta acciona algunos miedos en el profesor universitario pero quien ya arriesgó ponerla en práctica, percibió que los resultados valen la pena.

Esa propuesta no es para que el profesor deje de enseñar a escribir un proyecto durante el semestre, tampoco para que el profesor lleve a los alumnos a trabajar en sus proyectos, además no exime al profesor de dar clases.

Las siguientes son las dos características básicas del trabajo en la graduación que hemos defendido en los últimos 20 años:

- La investigación es realizada durante el desarrollo de la disciplina, desde el primer día de clases, considerándose el 
espacio físico en que la clase se desarrolla como un espacio en que también se investiga.

- Lo que el alumno aprende a hacer es la propia investigación y no un texto específico como un proyecto que tiene gran probabilidad de no ser desarrollado en el siguiente semestre. Tampoco trata de hacer un artículo que, aunque parezca estar vinculado a una investigación por ser considerado el texto adecuado para comunicar resultados de investigación, no refleja necesariamente el desarrollo de una reflexión propia por parte de quien lo escribió (BARZOTTO 2012).

Por ese concepto, la investigación necesita ser un componente de formación a lo largo del curso y no una actividad extracurricular. El alumno pasa a tener en esa práctica un lugar que posibilita mover el conocimiento teórico para analizar y discutir un tema y/o un dato que le interese en términos de objeto de estudio. El profesor, en la universidad, asume la posición de interlocutor, no en el sentido de asumir posiciones iguales, sino como aquel que toma la palabra del alumno como un campo fértil para la creación.

En esa perspectiva, la opción teórica del profesor no debe ser tomada como algo que debe ser seguido por el graduando como una profesión de fe, mucho menos su objeto de estudio. Obviamente, las referencias teóricas acontecen una vez que los sujetos, por constituirse en los procesos de interacción, toman el discurso de otro, sus valores sociales, ideológicos y culturales como punto de interlocución. Sin embargo, es fundamental que el alumno sepa que puede y debe tener un tema propio para responder.

La elección, el trabajo para elaborar y responder a un tema que le sea propio, fruto de una inquietud, es algo que se aprende y que permite la construcción de la experiencia, y lleva su propia inscripción en el texto.

Esa propuesta, aunque sea basada en concepciones diferentes, se asemeja al que Perrenoud (2002) define como aprendizaje por problemas. Este permite al alumno buscar conceptos, teorías o herramientas para resolver el problema de investigación con más recursos. O sea, los aportes teóricos y metodológicos pasan a ser, efectivamente, medios de construcción de respuestas para las 
preguntas, una vez que son comprendidos en la confrontación con situaciones locales y que no se configuran solamente con abstracciones. En ese proceso, el sujeto se ve obligado a tomar decisiones, seguir un norte, argumentar a favor en contra a un tema.

La investigación en la graduación es una situación creadora porque perturba, problematiza y desequilibra tanto al sujeto como el lenguaje. Principalmente, desestabiliza la condición de lector consumidor y reproductor de textos tan vigentes en los días actuales. La idea es que aquel que está en formación necesita, en las vivencias formativas, aprender a mover los saberes de la cultura y, poniendo su cuerpo y su singularidad en juego, en diálogo con esos saberes que le son dados, produce en su momento nuevos significados, nuevos sentidos (RIOLFI, 2007).

En ese sentido, la escritura no es una actividad que resulta de lo aprendido acerca de cómo comunicar ideas con claridad y precisión, mucho menos es solamente lo aprendido de las reglas estructurales de producción de un texto adecuado a la variedad patrón. La escritura por la concepción de investigación aquí defendida pasa a ser el centro a través del cual la formación se da, y ésta obliga al sujeto a organizar en el papel diversas operaciones discursivas que no se reducen, y mucho menos se definen como único dominio de la estructura de la lengua. Acciones para componer un texto exigen que sepa argumentar con su tiempo, que tenga conocimiento de los saberes y valores culturales, sociales e ideológicos vigentes en el contexto de producción.

Escribiendo, el futuro profesor aprende a dialogar con los valores dados por la sociedad y, sobre todo, aprende a interpretar, organizar todo eso en una pieza textual constituida y constitutiva de su propio lenguaje con respecto al objetivo del conocimiento, o acerca del tema en investigación. El trabajo con los recursos lingüísticos y extralingüísticos es lo que hace con que el texto, cuando es terminado, no sea un puñado de enunciados verbales en la superficie de un papel.

Desde esa perspectiva, la escritura resulta incómoda, a tal grado que el sujeto es obligado a hacerse a sí mismo la siguiente pregunta cuando se encuentra con el desarrollo de una investigación: ¿qué voy a decir sobre ese asunto? 
Afrontando el trabajo de leer la palabra de otro y producir una palabra propia, el futuro profesor, en la búsqueda de respuesta a una pregunta de investigación, gana condiciones para percibir y construir los movimientos necesarios de inscripción de su propia palabra en los dichos y discursos de la cultura académica, construyendo con eso, un camino nuevo para él y para las prácticas de enseñanza que podrá desarrollar en la escuela.

Es importante resaltar que lo nuevo, en la perspectiva aquí defendida, no es aquello que aún está por ser descubierto. La experiencia que el trabajo posibilita con la escritura o investigación con lo nuevo, ocurre porque su relevancia no acontece solamente de la afirmación que da una posición, ni de la capacidad de oposición a lo que está dicho, construido a base de saberes y valores culturales y sociales; ni de la imposición de una idea, ni de la sagacidad para la proposición, sino del coraje de cada uno en exponerse y, consecuentemente, asumir todo lo que eso retoma en términos de vulnerabilidad, riesgo, sustos y placer (LARROSA, 2004). 
Investigación, escritura y formación inicial del profesor

\section{Referencias}

BAKHTIN, M. (1979). Estética de la creación verbal. Trad. Paulo Bezerra. Sao Paulo: Martins Fontes, 2003.

. (1929) Marxismo y filosofía del lenguaje. Trad. Michel Lahud \& Yara Frateschi Vieira. Sao Paulo: Hucitec, 1995.

BARZOTTO, V (et all). Lectura, escritura e investigación en la graduación en Letras - análisis del Discurso de textos académicos. Curitiba: Appris Editora, 2012.

LARROSA, J. lenguaje y educación después de Babel. Belo Horizonte: Auténtica, 2004.

MAIA, M. S. “Texto de presentación”. In: PERROTTA, C. Un texto para llamar lo suyo - preliminares sobre la producción del texto académico. Sao Paulo: Martins Fontes, 2004

MARCUSCHI, L. A. Producción textual, análisis de géneros y comprensión. Sao Paulo: Parábola, 2008.

PERRENOUD, P. et. Al. Las competencias para enseñar en el siglo XXI: la formación de los profesores y el desafío de la evaluación. Porto Alegre: Artmed, 2002.

PERROTTA, C. Un texto para llamar lo suyo - preliminares sobre la producción del texto académico. Sao Paulo: Martins Fontes, 2004

PONZIO, A. Buscando otra palabra. Sao Carlos: Pedro \& Joao Editores, 2010.

CORACINI, M. J. R. "Discurso y escritura: entre la necesidad y la (im) posibilidad de enseñar". In: ECKERT-HOFF, B. M.; CORACINI, M. J. R. F. La escritura misma, y la alteridad en el espacio de la pantalla de papel. Campinas: Mercado de Letras, 2010.

RIOLFI. C. "Rupturas en la escritura, sorpresas para quien escribe: la ruta subjetiva en la formación del profesor de lengua portuguesa". 
Marinalva Vieira Barbosa

In: CALIL, E. (Org.). Pistas de la Escritura-Autoría, lectura y enseñanza. Sao Paulo: Cortez, 2007, v. 1, p. 15-32.

SCHNEIDER, M. Ladrones de palabras - ensayo sobre el plagio, el psicoanálisis y el pensamiento. Campinas: Editora de la UNICAMP, 1990.

WINNICOTT, D. W. (1990i). Carta 25 - Para Melanie Klein. In D. Winnicott (1990/1987b), El gesto espontáneo. Sao Paulo: Martins Fontes. 